\title{
OPEN GEOSPATIAL DATA FOR URBAN GREEN AREAS
}

\author{
Martina Baučić1, Frane Gilić ${ }^{1, *}$, Samanta Bačić ${ }^{1}$, Tea Duplančić-Leder ${ }^{1}$ \\ ${ }^{1}$ Faculty of Civil Engineering, Architecture and Geodesy, Split, Croatia - (mbaucic, fgilic, sbacic, tleder)@gradst.hr
}

\author{
Commission IV
}

KEY WORDS: geospatial open data, green infrastructure, green view index, Google Street View, land cover, Sentinel, urban, vegetation

\begin{abstract}
:
More than half of the world's population lives in big urbanized areas. It is not rare that those areas are lacking natural green spaces. Green spaces improve different aspects of life in cities and they are becoming so important that lately more and more attention is given to the so-called green infrastructure. The first step in planning green infrastructure is acquiring information about current city greenery. In this paper, it was investigated how can airborne, spaceborne, and street-level images be used in gathering information about greenery. As spaceborne images, Sentinel-2 satellite images were used and as street-level images, Google Street View $360^{\circ}$ photospheres have been utilized. From both sources, information about current greenery status was automatically extracted. Gathered data was aggregated on different spatial units that are suitable for decision making that aims at further developing the green spaces. These top-down and street-level images complement each other in a way that top-down images can be used to track the percentage of green area and its changing over time, while street-level images give information about greenery that is perceived by pedestrians. With proposed methods, it is possible to detect areas that should be considered for greening and also to identify areas that should have priority in that process.
\end{abstract}

\section{INTRODUCTION}

At present, the green spaces in cities are given an important role in contributing to sustainable development, adapting to climate change, development of green economy, and enhancing social cohesion (Hansen et al., 2017). The number of people living in the cities is rising, from $55 \%$ today to an estimated $60 \%$ by the year 2030 (United Nations, 2018). The European Commission published a Green Infrastructure Strategy (European Commission, n.d.) trying to ensure that green infrastructure (GI) becomes a part of urban areas development at all spatial scales: from a regional and national level to local; and in both settings: rural and urban.

GI planning is based on four principles: green-grey integration, connectivity, multi-functionality, and social inclusion (Hansen et al., 2017). Green areas could be linked with stormwater infrastructure and thus reduce water volumes in systems. In transport infrastructure, green areas may serve to mitigate noise, improve air quality, and provide pathways for biking and walking. Multi-functionality considers that green areas are delivering multiple services and thus ecological, social, and economic benefits to the cities. The social inclusion principle brings collaborative and participatory planning of GI.

The main urban challenges addressed by GI (Hansen et al., 2017) are urban areas adaptation to climate change is manifold: summer heatwaves, stormwater volumes, coastal erosions, and sea floods risks. Urban green spaces offer opportunities to the green economy too, via ensuring a pleasant environment for residents, businesses, and tourists. Green areas in cities are ranging from parks and urban forests to private gardens. Project Green Surge developed a green space typology of 44 GI elements, grouped in 8 groups (Cvejić et al. 2015). Water elements such as lakes, ponds, rivers, or coast are considered as GI elements and called Blue spaces. Additionally, GI elements are linked to GI ecosystems services. Two important characteristics of GI elements are: their connectivity and ownership (private or public).
An assessment of existing green and blue spaces is the first step in the planning of GI (Kilbane et al., 2018). All types of green and blue areas should be assessed including private and public land and describing the quantity, quality, distribution, services providing by the green areas and other properties. The aim is to build a knowledge base and support GI development.

Butlin et al. (2011) discuss the value of GIS in mapping GI to a range of planning projects. The key issue is to define the right type of information and resolution that can be used by the planning levels. Two mappings of GI are necessary: typology and functionality mapping. The geospatial data sets used for mapping were: aerial imagery of high resolution $-25 \mathrm{~cm}$, and digital surface and terrain models. Two important properties were derived for each parcel: the percentage of green areas and the percentage of tree cover in each parcel.

Dennis et al. (2018) presented an approach in mapping GI by use of Copernicus Sentinel 2A satellite imagery that is open-source, having high spatial and temporal resolution and global coverage. Land cover classification is done by a supervised classification using training samples, enhanced with land use data which derived the 35 landscape types for urban areas.

In the context of a hierarchy of GI planning, from regional to neighborhood (sub-city) level, GI elements vary (Davies et al., 2015) Considering GI elements, Copernicus Sentinel 2A satellite imagery together with local data (parcels, census units, etc.), as suggested by Dennis et al. (2018) are providing all except street scenes.

Investigating vegetation from airborne and spaceborne imagery generally can't give information about the perception of greenery from the pedestrian point of view. Manual methods for gathering data about greenery that is perceived from the pedestrian point of view are extremely time-consuming and expansive. To fill that gap, $\mathrm{Li}$ et al. (2015) explored Google Street View (GSV) as an urban greenery assessment tool on street-level. They modified the Green

\footnotetext{
* Corresponding author
} 
View Index (GVI) formula and measured street greenery using GSV images. Using freely available Google Street View (GSV) images make that process straightforward. By employing computer vision algorithms on GSV images, information about greenery is obtained effortlessly. Those data can then be used as an input for urban planning and greening projects.

GI mapping for large scale and urban areas is a comprehensive and expensive task, considering all the GI elements, their types, and functions as listed in Cvejić et al. (2015). Moreover, GI data should serve not only for GI planning but also for development and monitoring. Thus, the mapping should be repeated regularly, for example yearly.

This paper aimed to investigate the use of two open data sources and to evaluate their suitability for GI planning and monitoring. Sentinel imagery was used for vegetation mapping and GSV for street greenery mapping Also, consideration was given to the selection of spatial units for data aggregation appropriate for further input in the GI planning and development process.

The paper proposes aggregation of vegetation data to spatial units of urban plans: planned land use classes. The results show that the calculation of the GVI index together with its proposed aggregation is providing valuable data for GI planning and further monitoring. The paper further proposes the aggregation of GVI on two levels/two spatial units: settlements and street level.

\section{MATERIALS AND METHODS}

\subsection{Study area}

The study area of the City of Kaštela is located in the middle of the eastern coast of the Adriatic Sea. It includes 7 settlements with a population of about 40,000 people over $56 \mathrm{~km}^{2}$ (Figure 1). The analysis described in the paper is focused on an urban area that covers $24 \mathrm{~km}^{2}$ and stretches along $23 \mathrm{~km}$ of coastline (according to the official General Urban Plan (City of Kaštela, 2012)).

Coastal area is low and natural hilly areas are stretching inland. Coastline by type was mapped by Baučić et al. (2019) and $51 \%$ is concrete coast, $16 \%$ made of stone boulders, $13 \%$ is pebble, $2 \%$ is sand and $16 \%$ is natural coast. Thus only $3.7 \mathrm{~km}$ is the natural coast and represents the GI element.

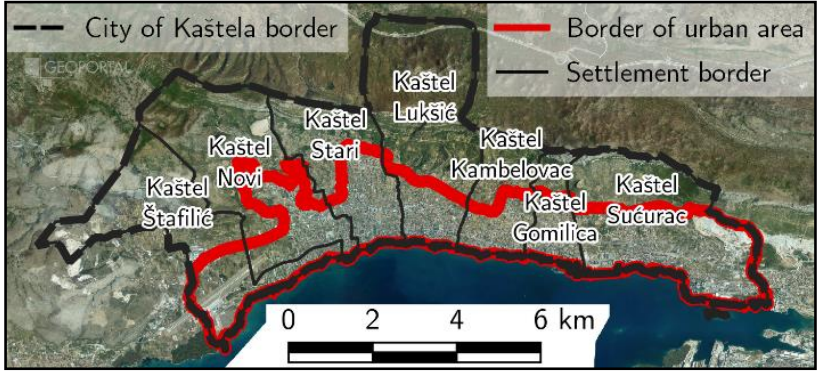

Figure 1. The study area of the City of Kaštela with seven settlements (aerial imagery (C) State Geodetic Administration of Croatia)

For the study area, planned land use and administrative borders were obtained from the official General urban plan (City of Kaštela, 2012) in scale 1:10,000. Green areas are present in the urban areas and considered under several categories of planned land use (City of Kaštela, 2012). Their mappings to the typology of GI and area they cover are given in Table 1. In total, they cover $4.99 \mathrm{~km} 2$ and that is $20.54 \%$ of the urban area.

An important characteristic of the study area is its vulnerability to storm waters. During storms and extreme precipitations, the lowest urbanized zone is flooding. It is due to superimposing of the impacts coming from the sea level rise (up to $80 \mathrm{~cm}$ during storms (Margeta et al. 2019)), torrents coming from hilly areas, urban storm waters, and underground waters. One of the proposed solutions given in (Margeta et al. 2019) is to map GI elements, their typology, and functionality. In this study area, GI planning should be accommodated for a local and urban scale.

\subsection{Green View Index (GVI) calculation}

2.2.1 Google Street View Images. In the late summer and early autumn of 2011. Google acquired the so-called Google Street View (GSV) $360^{\circ}$ photosphere images in the area of the City of Kaštela. Those panoramic images were gathered by imaging systems that consist of multiple cameras whose fields of view cover the whole area that can be seen from the acquisition point. Images can be downloaded through Street View Static API (Google, n.d.) by HTTP request and defining URL parameters. Currently, it is possible to freely download up to around 28,000 images within one month. The whole photosphere cannot be downloaded, but only patches of maximum field of view of $120^{\circ}$ and maximum image size of 640 x 640 pixels. URL parameters also

\begin{tabular}{|c|c|c|c|}
\hline GI group & Elements & $\begin{array}{l}\text { Corresponding planned land use } \\
\text { category (General urban plan) }\end{array}$ & Area in ha \\
\hline Natural, semi-natural and feral areas & $\begin{array}{l}\text { forest (e.g., remnant woodland, } \\
\text { managed forests, mixed forms) } \\
\text { forest (e.g., remnant woodland, } \\
\text { managed forests, mixed forms) } \\
\text { sand pit, quarry, open cast mine }\end{array}$ & $\begin{array}{l}\text { other farmland, forests and forest } \\
\text { land } \\
\text { protective green and landscape } \\
\text { areas } \\
\text { exploitation area }\end{array}$ & $\begin{array}{c}12.68 \\
102.84 \\
56.1\end{array}$ \\
\hline Parks and recreation & $\begin{array}{c}\text { large urban park } \\
\text { historical park/garden } \\
\text { cemetery and churchyard } \\
\text { green sport facilities }\end{array}$ & $\begin{array}{c}\text { public green areas } \\
\text { archeological park } \\
\text { graveyard } \\
\text { sport and recreational use }\end{array}$ & $\begin{array}{c}6.0 \\
6.6 \\
20.61 \\
8.08\end{array}$ \\
\hline Agricultural land & $\begin{array}{l}\text { tree meadow/orchard } \\
\text { tree meadow/orchard } \\
\text { tree meadow/orchard }\end{array}$ & $\begin{array}{c}\text { especially valuable farmland } \\
\text { other farmland } \\
\text { valuable farmland }\end{array}$ & $\begin{array}{c}129.00 \\
117.11 \\
41.96\end{array}$ \\
\hline \multicolumn{3}{|r|}{ Total land GI } & $500.98 \mathrm{ha}\left(5 \mathrm{~km}^{2}\right)$ \\
\hline Blue spaces & $\begin{array}{l}\text { river, stream } \\
\text { canal } \\
\text { coast }\end{array}$ & $\begin{array}{l}\text { Natural streams } \\
\text { Canal } \\
\text { Coastline (natural) }\end{array}$ & $\begin{array}{l}\text { unknown } \\
\text { unknown } \\
3.7 \mathrm{~km}\end{array}$ \\
\hline
\end{tabular}

Table 1. Planned land use - mappings to GI elements 
include coordinates of the location, and by default, the image is returned from the closest acquisition point within the $50 \mathrm{~m}$ radius from the defined location. By inspecting the Google Street View images within the Google Maps application, it is possible to notice that there are newer $360^{\circ}$ panoramic images in the area of the City of Kaštela, but those images were not gathered by Google, but by other organizations/individuals, and cannot be downloaded through Street View Static API.

2.2.2 Calculation of Green View Index (GVI). Street network for the City of Kaštela was downloaded from the OpenStreetMap (OSM) data. Figure 2 shows streets that are covered with GSV images and all streets from OSM data. It can be seen that the GSV platform (car, bike, etc.) did not pass through all the streets in the OSM street network. One reason is the fact that OSM street network includes not only streets that are designated for road vehicles, but also streets that are accessible only by pedestrians. Table 2 shows all street lengths from the OSM data, lengths of the streets from the OSM data that are covered by the GSV images and GSV coverage percentage for each of the seven settlements.

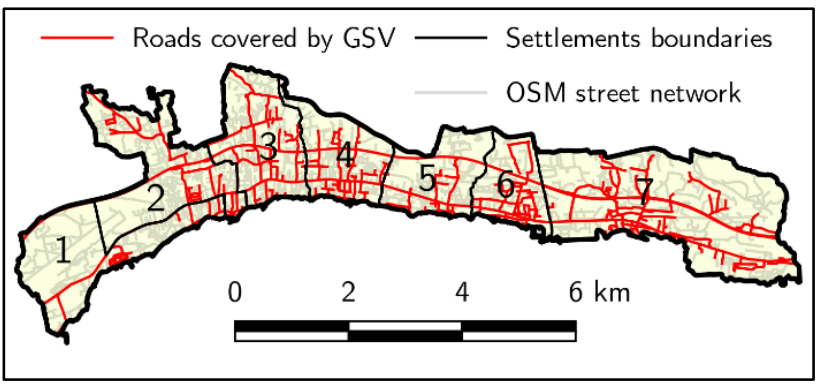

Figure 2. GSV coverage, OSM street network, and settlements urban area boundaries (settlement numbers correspond to numbers in Table 2)

\begin{tabular}{|c|c|c|c|c|c|}
\hline $\begin{array}{c}\text { Settlement } \\
\text { number }\end{array}$ & $\begin{array}{c}\text { Settlement } \\
\text { name }\end{array}$ & $\begin{array}{c}\text { Streets } \\
\text { length }\end{array}$ & $\begin{array}{c}\text { GSV } \\
\text { covered } \\
\text { streets } \\
\text { length }\end{array}$ & $\begin{array}{c}\text { GSV } \\
\text { coverage } \\
\text { percentage }\end{array}$ & $\begin{array}{c}\text { Number of } \\
\text { GSV } \\
\text { acquisition } \\
\text { sites }\end{array}$ \\
\hline 1 & K. Štafilić & $38,3 \mathrm{~km}$ & $10,2 \mathrm{~km}$ & $27 \%$ & 612 \\
2 & K. Novi & $46,3 \mathrm{~km}$ & $16,4 \mathrm{~km}$ & $35 \%$ & 1181 \\
3 & K. Stari & $42,7 \mathrm{~km}$ & $16,4 \mathrm{~km}$ & $38 \%$ & 1214 \\
4 & K. Lukšić & $31,8 \mathrm{~km}$ & $12,5 \mathrm{~km}$ & $39 \%$ & 964 \\
5 & K. Kambelovac & $26,0 \mathrm{~km}$ & $8,3 \mathrm{~km}$ & $32 \%$ & 626 \\
6 & K. Gomilica & $24,5 \mathrm{~km}$ & $12,2 \mathrm{~km}$ & $50 \%$ & 891 \\
7 & K. Sućurac & $81,3 \mathrm{~km}$ & $32,9 \mathrm{~km}$ & $40 \%$ & 2457 \\
\cline { 4 - 6 } & \multicolumn{2}{r|}{$290,9 \mathrm{~km}$} & $108,9 \mathrm{~km}$ & $37 \%$ & 7945 \\
\cline { 5 - 6 }
\end{tabular}

Table 2. Streets lengths, GSV covered streets lengths, GSV coverage percentage for each settlement, and number of GSV acquisition sites

Researchers at the MIT Senseable City Lab have developed an algorithm (Li et al., 2014) for calculating the percentage of the greenery from the GSV images and started the Treepedia portal (MIT Senseable City Lab, n.d.) for exploring the greenery in cities around the world. The original algorithm was partially changed (GitHub, n.d.) by researchers at the University of California, Irvine. This changed algorithm was used in this paper and some additional minor changes have been conducted (GitHub, 2020), primarily in the direction of speeding up the whole process.
Workflow for calculating the percentage of street greenery consists of three steps: extracting points from input shapefile with a street network, collecting metadata for nearest GSV acquisition point for each point that was obtained in the first step, and finally calculating the so-called Green View Index (GVI) from GSV images. GVI represents the percentage of the pixels that were classified as green vegetation from a number of all pixels in images for every GSV acquisition point. In the first step, points have been extracted along the lines in the OSM street network for approximately every $15 \mathrm{~m}$. In the second step, metadata were also collected using Street View Static API, and they include GSV site ID, acquisition date, and coordinates. Finally, in the last step, the calculation of the GVI is being conducted. As described by Li et al. (2015) and as can be seen from the source code (Li et al., 2014), GVI calculation is not carried out for the whole $360^{\circ}$ photosphere, but for six patches whose field of view, both horizontal and vertical, is $60^{\circ}$. Pitch for all images is set to $0^{\circ}$, which means that on each GSV site, GVI is calculated from images that cover $360^{\circ}$ stripe with elevation from $-30^{\circ}$ to $+30^{\circ}$. GSV images are RGB images (Figure 4), so the green area has to be extracted from data in the red, green, and blue band. A detailed description can be found in Li et al. (2015).

Calculated GVI values were added to each GSV acquisition point whose coordinates were gathered during collecting metadata. For some GSV sites, GVI was calculated more than once, because the same site was identified as closest to more than one point that was extracted from input street network shapefile. After removing duplicated GSV sites from the resulting dataset, it turned out that GVI was calculated for 7987 GSV sites. It was noticed that for a couple of dozens of GSV sites, images were captured during the winter period of 2012 , and were also removed from the dataset since the winter period is not appropriate for greenery studying. In the final dataset, there are 7945 points.

Figure 5 depicts locations of all GSV acquisition sites within the study area. GSV site distribution over the settlements is listed in Table 2. Distance from final consecutive GSV sites, as can be seen in Figure 3, mostly ranges from 10 to 20 meters. GVI values vary from $1.5 \%$ to $56.9 \%$ with average GVI of approximately $21.6 \%$. Images from GSV sites that have minimum and maximum GVI value are shown in Figure 4.

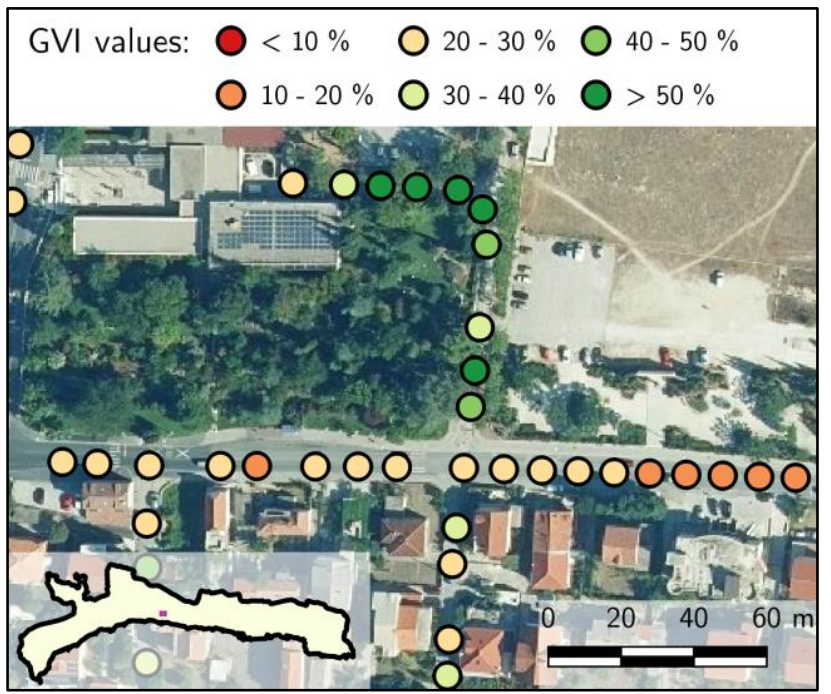

Figure 3. A closer look at the GSV acquisition sites (sites are colored by corresponding GVI value, aerial imagery (C) State Geodetic Administration of Croatia) 

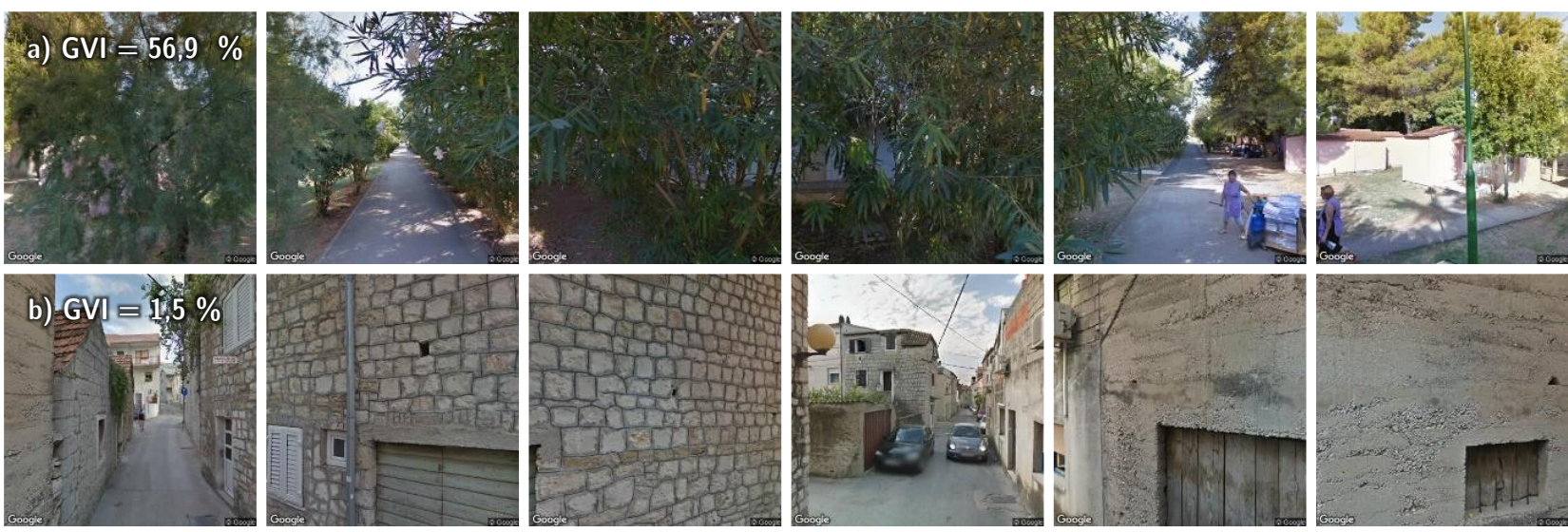

Figure 4. GSV $360^{\circ}$ stripes with (a) maximum and (b) minimum GVI value within the study area

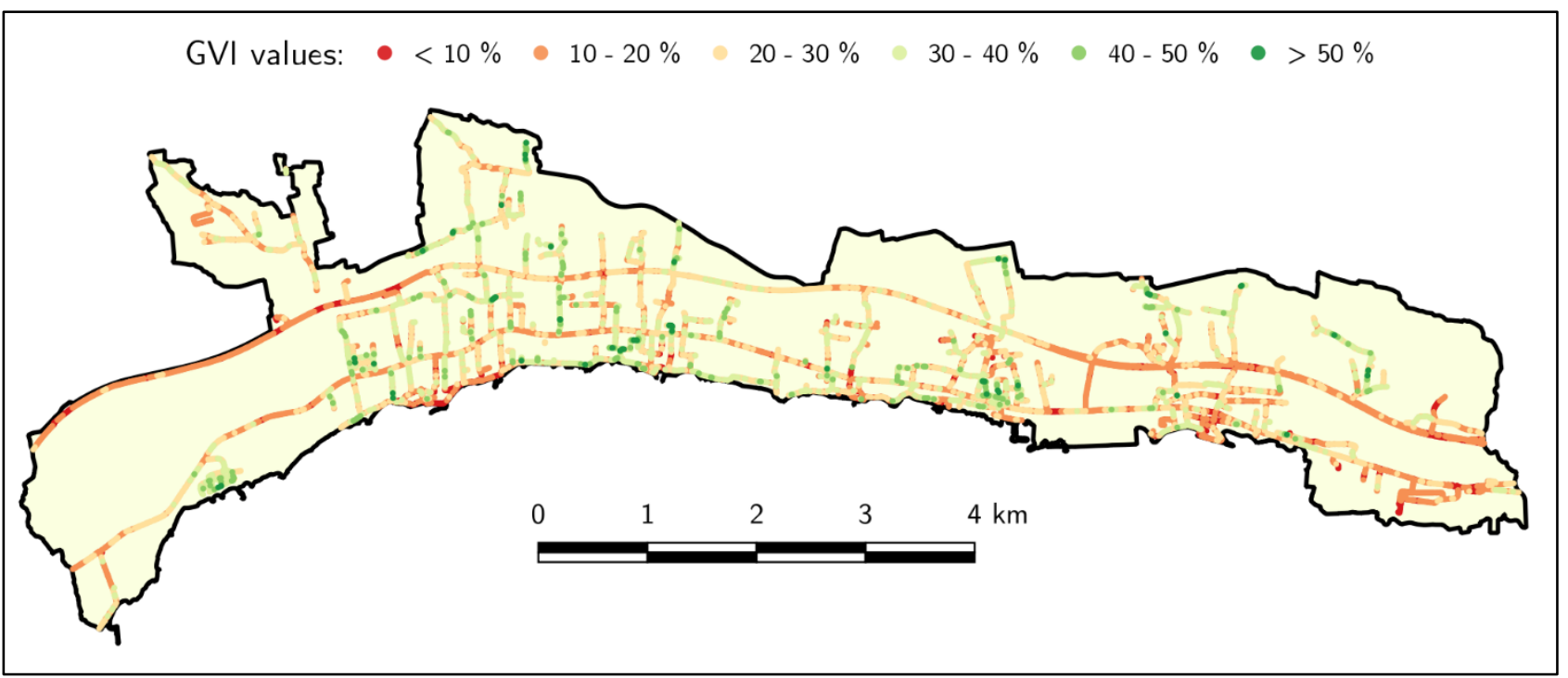

Figure 5. GSV acquisition sites colored by corresponding GVI values

\subsection{Vegetation calculation}

2.3.1 Sentinel-2. The Sentinel-2 mission consists of two satellites (Sentinel-2A and Sentinel-2B), developed to support vegetation, land cover, and environmental monitoring. Mission was launched by the European Space Agency (ESA) as a part of the Copernicus program (ESA, n.d.-a). Sentinel-2 data are available since 2015 and they can be downloaded on the official ESA Copernicus Scientific Data Hub website (ESA, n.d.-b).

The satellites are equipped with the MultiSpectral Instrument (MSI) which provides images with high spatial, spectral, and temporal resolution. MSI acquires 13 spectral bands ranging from Visible and Near-Infrared (NIR) to Shortwave Infrared (SWIR) wavelengths, with a swath width of $290 \mathrm{~km}$ (Drusch et al., 2012). The Sentinel-2 mission has a high revisit frequency of 5 days (Dennis et al., 2018).

For this paper, Sentinel-2 satellite images from August 7, 2015 and from August 6, 2019 were used, and band set with 10 and 20 $\mathrm{m}$ spatial resolution. By the combination of these bands, the input classification raster was created.

2.3.2 Land Cover Classification for vegetation extraction. Automatic land cover classification of Sentinel-2 data and data processing were done using the QGIS Semi-Automatic
Classification plugin (Congedo, 2016) for Sentinel-2, Sentinel-3, and Landsat mission data.

The land cover classification was made by selecting regions of interest (ROIs) study area polygon for 4 land cover classes: water class (1), built-up (2), vegetation (3), and bare soil (4). The classification plugin uses different algorithms (Richards and Jia, 2006). In this paper, the minimum distance algorithm was used, because it was giving the best results. After classification, the reclassification was performed to obtain the two classes: vegetation (1) and other areas (0). The reclassified raster is shown in figures 10 and 11. The same process was made for the Sentinel-2 scenes from 2015 and 2019.

\section{RESULTS}

\subsection{Green View Index (GVI) for GI planning}

Once GVIs are calculated, the question is what urban planning and particularly GI planning could benefit from that data. High GVIs mean more street greenery. Street greenery represents an important GI element that performs several functions. More shade areas on streets facilitate citizens to walk along streets during heatwaves. Greenery along streets provides a network of green corridors ensuring connectives among green areas such as parks, an important 
issue for urban habitats of many species. Finally, street greenery improves the quality of life and open business opportunities by making the urban landscape more pleasant (for citizens and also for business and tourists) and encourage physical activity.

This paper proposes two uses of GVIs in GI planning. One is in analyzing and comparing urban areas based on the total amount of street greenery and prioritizing greening activities. Another one is in analyzing selected streets and identifying parts with reduced greenery - interruptions in providing green corridors, and thus prioritizing these streets' parts for greening.

3.1.1 Street greenery in the settlements. For the study area, the urban area is divided into settlements, the lowest level of administrative units in Croatia having representatives and budget for communal works such as street and public spaces maintenance and improvements. Thus, GVIs are aggregated on that level and a short description of results follows.

Table 3 lists minimum, maximum, and average GVI values and also standard deviation of the GVI values for each of the seven settlements. Minimum GVI values vary from $1.5 \%$ to $2.9 \%$, maximum values from $49.3 \%$ to $56.9 \%$, and average values from $18.7 \%$ to $24.7 \%$. Standard deviations range from $8.0 \%$ to $9.7 \%$ which means that GVI values are almost equally scattered around average value for each settlement. Figure 6 depicts urban areas of each of the seven settlements colored by average GVI value. It can be seen that Kaštel Stari, Kaštel Lukšić, and Kaštel Gomilica have the largest average GVI values, while Kaštel Novi and Kaštel Sućurac have the smallest.

\begin{tabular}{|c|c|c|c|c|c|}
\hline $\begin{array}{c}\text { Settlement } \\
\text { number }\end{array}$ & $\begin{array}{c}\text { Settlement } \\
\text { name }\end{array}$ & $\begin{array}{c}\text { Min. } \\
\text { GVI }\end{array}$ & $\begin{array}{c}\text { Max. } \\
\text { GVI }\end{array}$ & $\begin{array}{c}\text { Average } \\
\text { GVI }\end{array}$ & $\begin{array}{c}\text { GVI stand. } \\
\text { deviation }\end{array}$ \\
\hline 1 & K. Štafilić & $2.9 \%$ & $56.9 \%$ & $22.4 \%$ & $9.7 \%$ \\
2 & K. Novi & $2.2 \%$ & $51.2 \%$ & $19.8 \%$ & $8.9 \%$ \\
3 & K. Stari & $2.8 \%$ & $53.1 \%$ & $24.4 \%$ & $9.4 \%$ \\
4 & K. Lukšić & $1.5 \%$ & $55.0 \%$ & $24.7 \%$ & $9.5 \%$ \\
5 & K. Kambelovac & $4.0 \%$ & $49.3 \%$ & $22.5 \%$ & $8.0 \%$ \\
6 & K. Gomilica & $2.9 \%$ & $54.1 \%$ & $24.0 \%$ & $9.4 \%$ \\
7 & K. Sućurac & $1.9 \%$ & $51.5 \%$ & $18.7 \%$ & $8.5 \%$ \\
\hline \multicolumn{1}{r}{} & $1.5 \%$ & $56.9 \%$ & $21.6 \%$ & $9.7 \%$ \\
\hline
\end{tabular}

Table 3. Minimum, maximum, average, and standard deviation of the GVI values for each of the seven settlements

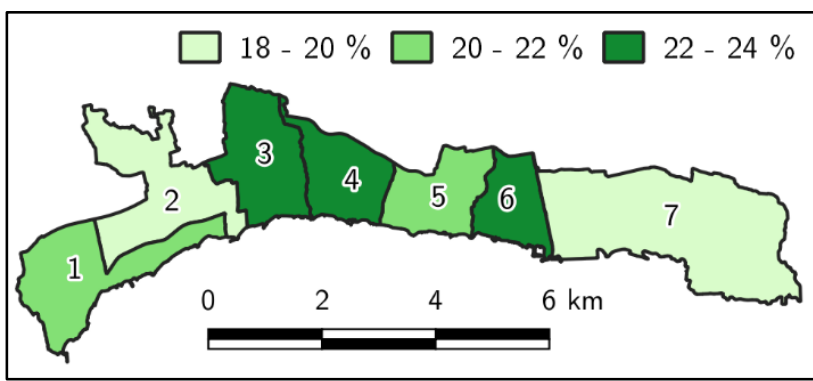

Figure 6. Urban area of the settlements colored by corresponding average GVI value (settlement numbers match to those in Table 3)

Figure 7 shows the relative frequency polygon of the GVI values for each settlement. GVI values have been divided into 10 equally sized bins. It can be seen that GVI values for all settlements are unimodal, with mode bins $[12,18)$ and $[18,24)$. In other words, most of the GVI values are concentrated between 12 and $24 \%$.

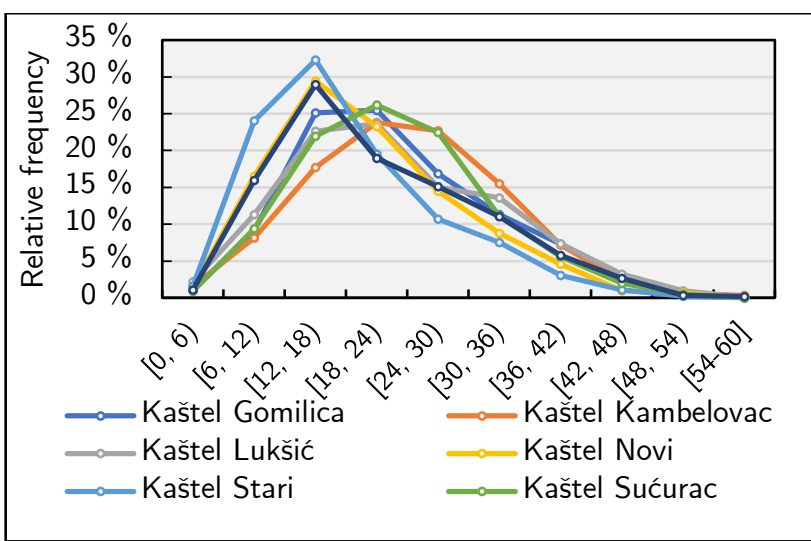

Figure 7. Relative frequency polygon of the GVI values in each of the seven settlements

The simple conclusion from gathered GVI data can be that future greening plans in the City of Kaštela should give precedence to settlements Kaštel Novi and Kaštel Sućurac because of their lowest average GVI value. If it is needed to define precise locations where current greenery should be, it is possible to detect points where GVI values are the smallest. Locations with small GVI values are mostly not suitable for planting new vegetation. So, another approach can also be to detect locations where points have GVI values from the mode bin in the histogram. If greenery is increased on those points and mode bin shifts to the following one, then average greenery in the whole village is also increased.

3.1.2 Interruptions in green corridors. In the City of Kaštela, three main longitudinal corridors connect all seven settlements: Cesta pape Ivana Pavla II., Cesta dr. Franje Tuđmana, and seaside promenade. Those three paths represent key corridors for connecting green areas and have been further analyzed to identify the interruptions in greenery, thus to be firstly considered by additional greening.

Figure 8 shows those three paths and locations (colored in red) that are recommended for further greening. These locations are identified by dividing routes into approximately 20 -meter long segments and then analyzing GVI values for consecutive segments. If GVI value for the particular segment has fallen for more than $30 \%$ from the average GVI value for the last two consecutive segments, than that segment is marked as the one that should be considered for greening. Every following segment is also marked for greening unless its GVI value is more than $30 \%$ higher than the average GVI value for the last two consecutive segments (GitHub, 2020). Table 4 lists lengths of each corridor, length of each corridor that is recommended for additional greening, and length of each corridor that has GVI value that is lower than the average GVI for the whole study area.

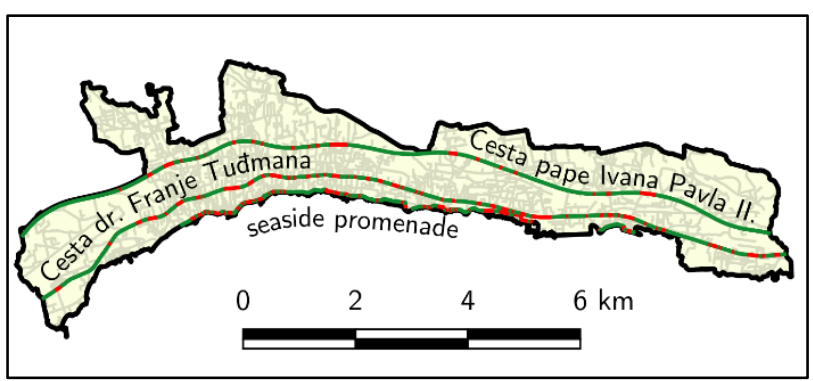

Figure 8. Three main corridors in the City of Kaštela and locations (red) that are recommended for additional greening 


\begin{tabular}{|c|c|c|c|}
\hline Corridor & Length & $\begin{array}{c}\text { Corridor length suggested for greening (red on } \\
\text { Figure 8) }\end{array}$ & $\begin{array}{c}\text { Corridor length that has GVI lower than the } \\
\text { average GVI for the whole study area }\end{array}$ \\
\hline Cesta pape Ivana Pavla II. & $14.02 \mathrm{~km}$ & $1.80 \mathrm{~km}(12.8 \%)$ & $11.12 \mathrm{~km}(79.3 \%)$ \\
Cesta dr. Franje Tuđmana & $14.16 \mathrm{~km}$ & $4.44 \mathrm{~km}(31.7 \%)$ & $9.12 \mathrm{~km}(64.4 \%)$ \\
seaside promenade & $7.52 \mathrm{~km}$ & $2.76 \mathrm{~km}(36.7 \%)$ & $3.34 \mathrm{~km}(44.4 \%)$ \\
\cline { 2 - 4 } & $35.70 \mathrm{~km}$ & $9.00 \mathrm{~km}(25.2 \%)$ & $23.58 \mathrm{~km}(66.1 \%)$ \\
\hline
\end{tabular}

Table 4. Lengths of each corridor, and lengths of the corridors that are suggested for additional greening, and that have lower GVI than the average GVI value on the whole study area

\subsection{Vegetation land cover data for the GI planning}

Vegetation extracted from Sentinel imagery for the year 2015 and 2019 was overlapped with planned land use data of the City of Kaštela obtained from the official General Urban Plan (City of Kaštela, 2012) in scale 1:10,000. Figure 9 presents vegetation from 2019 overlapped with planned land use zones.

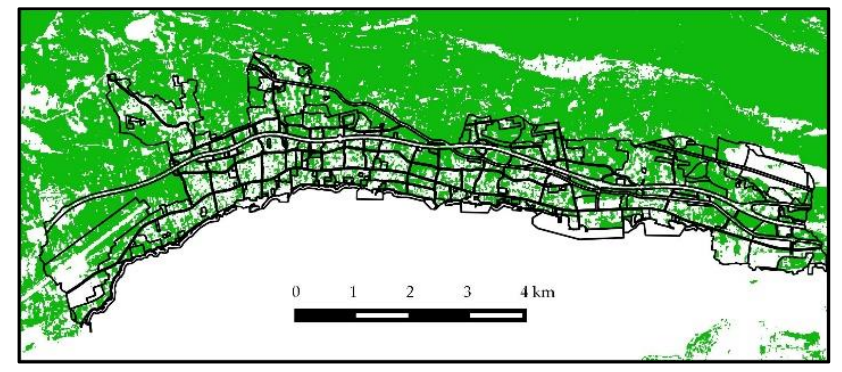

Figure 9. Overlap of vegetation for 2019 with land use
Table 5 presents the area and percentage of vegetation for each planned land use category for years 2015 and 2019. Additionally, changes that occurred in the vegetation in the period from 2015 to 2019 are calculated too. The significant change, i.e. the reduction of vegetation in 2019, is present in the areas that fall under the category 'catering-tourist and residential use'. This is expected given that tourism is developing rapidly and more and more tourist facilities are being built, which usually results in destroying vegetation.

Table 6 shows how many green areas are located within the planned areas which are also defined as GI elements and how many in other areas. The significant amount of vegetation is located outside planned land use categories considered as GI ( 3 times more) and at the same time potentially threatened because the vegetation is not protected - as already happened for the category 'catering-tourist and residential use' shown in Table 5. There are no significant changes in total percentages and areas, but looking at the GI elements, the vegetation is slightly increased while in other areas decreasing. Looking at the entire

\begin{tabular}{|c|c|c|c|c|c|c|c|}
\hline \multirow[b]{2}{*}{ Planned land use category } & \multirow[b]{2}{*}{$\begin{array}{c}\text { GI } \\
\text { elements }\end{array}$} & \multirow[b]{2}{*}{$\begin{array}{c}\text { Area } \\
\text { [ha] }\end{array}$} & \multicolumn{2}{|c|}{2015} & \multicolumn{2}{|c|}{2019} & \multirow{2}{*}{\begin{tabular}{|c|} 
Changes \\
2019-2015 \\
vegetation are \\
\end{tabular}} \\
\hline & & & $\begin{array}{c}\text { vegetation } \\
\text { area [ha] }\end{array}$ & $\%$ vegetation & $\begin{array}{c}\text { vegetation } \\
\text { area [ha] }\end{array}$ & $\%$ vegetation & \\
\hline mixed use & & 889.99 & 450.25 & 50.59 & 450.30 & 50.60 & 0.05 \\
\hline catering-tourist and residential use & & 161.64 & 85.92 & 53.15 & 66.18 & 40.95 & -19.73 \\
\hline $\begin{array}{l}\text { historical core, residential, } \\
\text { business, public, so }\end{array}$ & & 34.72 & 11.62 & 33.46 & 6.62 & 19.07 & -5.00 \\
\hline public and social use & & 27.63 & 10.71 & 38.75 & 8.81 & 31.88 & -1.90 \\
\hline mainly business use & & 63.90 & 38.79 & 60.70 & 38.92 & 60.91 & 0.13 \\
\hline economic use & & 57.76 & 21.18 & 36.67 & 16.93 & 29.32 & -4.25 \\
\hline hotel & & 31.74 & 14.13 & 44.52 & 11.92 & 37.55 & -2.21 \\
\hline sea port & & 11.84 & 3.95 & 33.33 & 2.05 & 17.32 & -1.90 \\
\hline public green areas & $\mathrm{x}$ & 6.04 & 3.19 & 52.91 & 2.21 & 36.66 & -0.98 \\
\hline protective green and landscape & $\mathrm{x}$ & 102.48 & 56.69 & 55.32 & 56.68 & 55.31 & -0.01 \\
\hline sport and recreational use & $\mathrm{x}$ & 8.08 & 4.34 & 53.70 & 4.11 & 50.88 & -0.23 \\
\hline exploitation area & $\mathrm{x}$ & 56.13 & 11.72 & 20.88 & 11.24 & 20.03 & -0.47 \\
\hline business-oriented (craft) use & & 31.78 & 13.19 & 41.49 & 11.09 & 34.88 & -2.10 \\
\hline swimming area & & 14.27 & 4.75 & 33.32 & 3.19 & 22.39 & -1.56 \\
\hline graveyard & $\mathrm{x}$ & 20.61 & 13.45 & 65.22 & 13.00 & 63.07 & -0.44 \\
\hline especially valuable farmland & $\mathrm{x}$ & 129.00 & 83.70 & 64.88 & 85.66 & 66.40 & 1.97 \\
\hline business use & & 33.06 & 16.15 & 48.84 & 16.07 & 48.60 & -0.08 \\
\hline infrastructure system area & & 127.76 & 71.99 & 56.35 & 75.60 & 59.17 & 3.61 \\
\hline corridors & & 275.03 & 133.96 & 48.71 & 133.40 & 48.50 & -0.56 \\
\hline other farmland, forests & $\mathrm{x}$ & 12.68 & 11.65 & 91.92 & 11.53 & 90.92 & -0.13 \\
\hline valuable farmland & $\mathrm{x}$ & 41.96 & 28.81 & 68.67 & 30.68 & 73.12 & 1.87 \\
\hline maritime zone & & 77.13 & 17.86 & 23.16 & 11.20 & 14.52 & -6.66 \\
\hline special purpose & & 13.70 & 7.85 & 57.28 & 5.92 & 43.22 & -1.93 \\
\hline swimming area & & 39.12 & 5.68 & 14.52 & 0.28 & 0.71 & -5.40 \\
\hline archaeological park & $\mathrm{x}$ & 6.56 & 3.15 & 48.07 & 3.48 & 53.11 & 0.33 \\
\hline other farmland & $\mathrm{x}$ & 117.11 & 91.54 & 78.17 & 93.81 & 80.11 & 2.27 \\
\hline mixed use in bathing function & & 6.13 & 2.12 & 34.67 & 1.57 & 25.65 & -0.55 \\
\hline tourist resort & & 27.94 & 10.83 & 38.77 & 8.49 & 30.38 & -2.34 \\
\hline utility service & & 3.74 & 1.42 & 38.06 & 1.90 & 50.81 & 0.48 \\
\hline
\end{tabular}

Table 5 . The area under vegetation by planned land use zones and vegetation changes 


\begin{tabular}{|c|c|c|c|c|}
\cline { 2 - 5 } \multicolumn{1}{c|}{} & \multicolumn{2}{c|}{2015} & \multicolumn{2}{c|}{2019} \\
\cline { 2 - 5 } \multicolumn{1}{c|}{} & vegetation area [ha] & \% vegetation & vegetation area [ha] & \% vegetation \\
\hline GI elements (planned land use category recognized & 308.25 & 62.63 & 312.43 & 63.40 \\
as GI element) & 922.34 & 49.18 & 870.45 & 48.36 \\
Other planned land use categories & 1230.59 & 50.10 & 1182.87 & 49.38 \\
Total in study area & &
\end{tabular}

Table 6 . The area under vegetation by planned land use - GI elements and other land use

study area, the area under vegetation has decreased by less than $1 \%$ from the year 2019 to 2015 .

As an objective quality measurement of the land cover classification, accuracy assessment was calculated. Overall accuracy for 2015 classification is $86 \%$, and for 2019 is $90 \%$. Additionally, the kappa coefficient (L3Harris, 2020) for 2015 is 0.72 and for 2019 is 0.80 . It is evident that the accuracy is better for 2019 than for 2015

Figure 10 shows the vegetation calculated from Sentinel imagery in residential area overlaid with planned land use categories (borders as black lines). Figure 10a presents a closer look at classification with Sentinel-2 data from 2015, and Figure 10b is the same representations for 2019 data. Figure 11 shows the vegetation calculated from Sentinel imagery along the main road, the area that belongs to the commercial area overlaid with planned land use categories. On Figure 11a is given the closer look at classification results with Sentinel-2 data from 2015, and in Figure 11b from 2019 data. Figures 10 and 11 are illustrating still coarse Sentinel spatial resolution for urban areas large scales. Also, it could be seen that residential areas are including small agricultural fields, sometimes classified as bare soil and sometimes as vegetation, up to the present gardening.

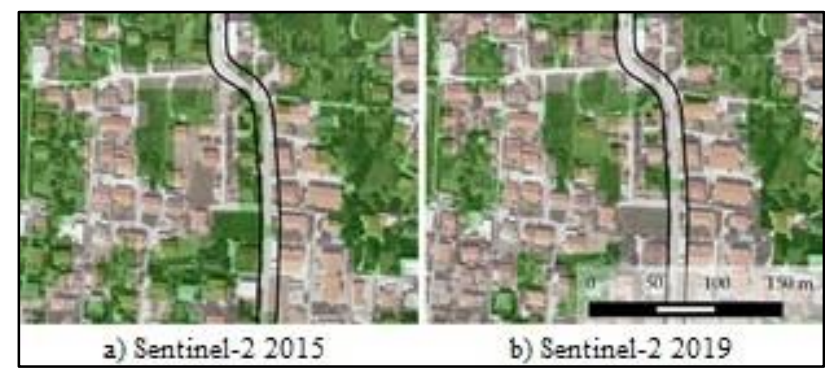

Figure 10. A closer look at classification results in the residential area - green areas show land under vegetation

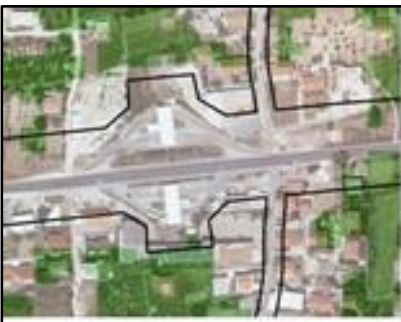

a) Sentinel-2 2015

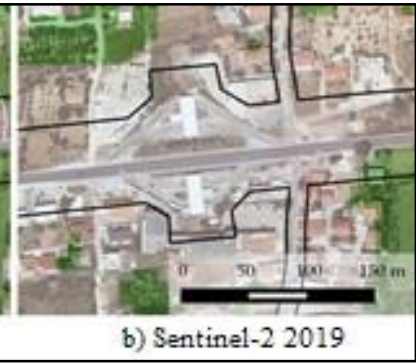

b) Sentinel-2 2019
Figure 11. A closer look at classification results in the commercial area - green areas show land under vegetation

\section{DISCUSSION AND CONCLUSIONS}

The results demonstrate the main advantaged and disadvantaged of the two global open data sources in GI mapping.
GVI index represents the percentage of street greenery and could serve in GI mapping and planning. To achieve this aim, the paper proposes two aggregations of the calculated GVIs based on two selected spatial units: settlements and streets. Settlements (or city blocks in more densely populated cities) are selected as spatial units having representatives, budget, and duties under city administration. Analyzing and comparing such urban areas based on the total amount of street greenery could help in prioritizing greening activities and ensuring the budget for that. Street-level is selected as it is a basic element constituting network and representing green corridors connecting green urban areas. The paper proposes a method of analyzing streets greenery and identifying parts with reduced greenery - interruptions in providing green corridors and thus prioritizing these streets' parts for greening.

The limitation of GVI is in its temporal aspect, GSV data is almost 10 years old. But, other providers are approaching the global market and therefore this could change in the near future.

The use of Sentinel imagery for vegetation identification is a valuable source of GI data for urban areas, but it is not the best solution for vegetation classification. Data can be improved by using better spatial resolution satellite images or unmanned aerial vehicle (UAV) images. An important advantage is Sentinel temporal resolution (5 days) that allows monitoring of changes in a short period, which is important in urban environments where changes are daily. The paper proposes aggregation of vegetation data to spatial units of urban plans: planned land use classes. Urban spatial plans define rules for each land use type - land use zone. Knowing the percentage of vegetation and how much each zone contributes to GI, even those zones not planned as green zones, could support decision making and realizing GI. Additionally, the efficiency of spatial rules could be monitored, e.g. percentage of a parcel that should be under vegetation and not sealed.

These two global and open data sources data; Sentinel and GSV, could serve worldwide as a basis for GI mapping and further integration with other sources of data, also globally or nationally available. Global maps could help in visual interpretation. Nationally available data such as socio-economic data aggregated to census units, or topographic and legal data aggregated to parcels, could help in mapping additional properties of GI elements such as types and functions. But, nationally available data varies a lot among the countries in its availably, up-to-dateness, and details.

Further research goals toward exploring other open-source data helping in mapping GI functions. For example, social media data showing people use of green areas and similar. Another direction could go in exploring other sources of street imagery including infra-red images and covering $360^{\circ}$ field of view collected on a regular basis. 


\section{ACKNOWLEDGEMENTS}

This research is partially supported through project KK.01.1.1.02.0027, a project co-financed by the Croatian Government and the European Union through the European Regional Development Fund-the Competitiveness and Cohesion Operational Programme.

\section{REFERENCES}

Baučić, M., Ivić, M., Jovanović, N., Bačić, S., 2019: Vulnerability analysis for the integrated coastal zone management plan of the City of Kaštela in Croatia. Int. Arch. Photogramm. Remote Sens. Spat. Inf. Sci., XLII-3/W8, 59-63, doi.org/10.5194/isprs-archives-XLII-3-W8-59-2019.

Butlin, T., Chambers, C., Ellis, F., 2011: The Value of Mapping Green Infrastructure. The Mersey Forest, Royal Institution of Chartered Surveyors - Surveyor Court, Westwood Business Park, Coventry CV4 8JE, UK.

City of Kaštela, 2012: Generalni urbanistički plan Grada Kaštela. Available at: https://www.kastela.hr/dokumenti (accessed 12 May 2020).

Congedo, L., 2016: Semi-Automatic Classification Plugin Documentation. Release 6.0.1.1. doi.org/10.13140/RG.2.2. 29474.02242/1

Cvejić, R., Eler, K., Pintar, M., Železnikar, Š., Haase, D., Kabisch, N., Stronbach, M., 2015: A typology of urban green spaces, ecosystem provisioning services and demands. GREEN SURGE, Report D3.1. Available at: https://www.epages.dk/ku/1334/html5/ (accessed 6 July 2020).

Davies, C., Macfarlane, R., Mcgloin, C., Roe, M., 2015: Green Infrastructure Planning Guide. doi.org/10.13140/RG.2.1.1191. 3688 .

Dennis, M., Barlow, D., Cavan, G., Cook, P.A., Gilchrist, A., Handley, J., James, P., Thompson, J., Tzoulas, K., Wheater, C.P., Lindley, S., 2018: Mapping Urban Green Infrastructure: A Novel Landscape-Based Approach to Incorporating Land Use and Land Cover in the Mapping of Human-Dominated Systems. Land, 7, 1-25. doi.org/10.3390/land7010017.

Drusch, M., Del Bello, U., Carlier, S., Colin, O., Fernandez, V., Gascon, F., Hoersch, B., Isola, C., Laberinti, P., Martimort, P., Meygret, A., Spoto, F., Sy, O., Marchese, F., Bargellini, P., 2012: Sentinel-2: ESA's Optical High-Resolution Mission for GMES Operational Services. Remote Sensing of Environment, 120, 2536. doi.org/10.1016/j.rse.2011.11.026.

ESA, n.d.-a, Sentinel Online, Sentinel-2. Available at: https:// sentinel.esa.int/web/sentinel/missions/sentinel-2 (accessed 12 May 2020).

ESA, n.d.-b: Copernicus Open Access Hub. Available at: https:// scihub.copernicus.eu/dhus/\#/home (accessed 5 May 2020).

European Commission, Environment, The EU Strategy on Green Infrastructure. Available at: https://ec.europa.eu/environment /nature/ecosystems/strategy/index_en.htm (accessed 10 May 2020).
GitHub, n.d.: GVI-Calculator. Available at: https://github. com/the-rango/GVI-Calculator (accessed 12 May 2020).

GitHub, 2020: GVI-Calculator. Available at: https://github. com/fgilic/GVI-Calculator (accessed 6 July 2020).

Google, Google Maps Platform, Street View Static API, Developer Guide. Available at: https://developers.google.com /maps/documentation/streetview/intro (accessed 12 May 2020).

Hansen, R., Rall, E., Chapman, E., Rolf, W., Pauleit, S., 2017: Urban Green Infrastructure Planning: A Guide for Practitioners. GREEN SURGE. Available at: https://www.epages.dk/ku/1340/html5/ (accessed 6 July 2020).

Kilbane, S., La Rosa, D., 2018: Urban Green Infrastructure: a study of type, opportunity and constraints for greater urban resilience. MDPI AG, IFoU 2018: Reframing Urban Resilience Implementation: Aligning Sustainability and Resilience, proceedings, 10/12/2018 - 12/12/2018, Barcelona, Spain. doi.org/10.3390/IFOU2018-06024.

L3Harris, 2020: Calculate Confusion Matrices. Available at: https://www.harrisgeospatial.com/docs/CalculatingConfusionM atrices.html (accessed 8 July 2020).

Li, X., Seiferling, I., Abdulhai, M., 2014: Treepedia Public. Available at: https://github.com/mittrees/Treepedia_Public (accessed 12 May 2020).

Li, X., Zhang, C., Li, W., Ricard, R., Meng, Q., Zhang, W., 2015: Assessing street-level urban greenery using Google Street View and a modified green view index. Urban Forestry \& Urban Greening, 14(3), 675-685. doi.org/10.1016/j.ufug.2015.06.006.

Margeta, J., Vilibić, I., Jakl, Z., Marasović, K., Petrić, L., Mandić, A., Grgić, A., Bartulović, H., Baučić, M., 2019: Draft version: Coastal Action Plan for the City of Kaštela. Technical Report, JU RERA, Split, Croatia.

MIT Senseable City Lab: Treepedia portal. Available at: http://senseable.mit.edu/treepedia (accessed 12 May 2020).

Richards, J. A. and Jia, X., 2006: Remote Sensing Digital Image Analysis: An Introduction. Berlin, Germany: Springer.

United Nations, Department of Economic and Social Affairs, Population Division, 2018: The World's Cities in 2018. Data Booklet (ST/ESA/SER.A/417). doi.org/10.18356/c93f4dc6-en. 